\title{
FORMULATION AND EVALUATION OF ORAL SUSTAINED IN SITU GELLING SYSTEM OF ROXATIDINE
}

\author{
Mohammed Gulzar Ahmed*, Chirag Kapoor and Sanjana Adinarayana
}

\begin{abstract}
Yenepoya Pharmacy College \& Research Centre, Yenepoya University, Deralakatte 575018 India
\end{abstract}

Submitted:06-05-2017

Revised:17-06-2017

Accepted:22-07-2017

*Corresponding author

Mohammed Gulzar Ahmed

Email:

mohammedgulzar1@gmail.com

\begin{abstract}
Gel dosage forms are successfully used as drug delivery systems to control drug release and protect the medicaments from a hostile environment. The main objective of this present work is to formulate and evaluate in situ gels of roxatidine for the treatment of peptic ulcer. This system utilizes polymers that exhibit sol-to-gel phase transition due to change in specific physico-chemical parameters. In the present work in situ gels have been developed by using gellan gum and sodium alginate based on the concept of ion activated systems. Sol-to-gel transformation occurred in the presence of monovalent/divalent cations. Formulations were evaluated for clarity, drug content, in vitro gelling capacity, determination of $\mathrm{pH}$, in situ release study, viscosity, gel strength, ex vivo gelation and stability study. All the results found to be satisfactory. The experimental part showed that viscosity of sols and gel strength was increased with increase in the concentration of polymers, also drug release gets sustaining. The formulations were therapeutically efficacious, sterile and provided sustained release of the drug over a period of time. These results demonstrated that the developed system is an alternative to conventional drug delivery systems and can improve patient compliance.
\end{abstract}

Key words: In situ gels, roxatidine, peptic ulcer, in vitro, viscosity

\section{INTRODUCTION}

Over the past 30 years greater attention has been focused on the development of controlled and sustained drug delivery systems. The goal in designing these systems is to reduce the frequency of dosing or to increase the effectiveness of the drug by localization at the site of the action. Amongst the extensive research has been carried in designing of polymeric drug delivery systems, the development of in situ gel systems has received considerable attention over the past few years. These systems are capable of releasing the drug in a sustained manner maintaining relatively constant plasma profiles and they are liquid at room temperature but undergo gelation when in contact with body fluids or change in $\mathrm{pH}$. This is a characteristic property of temperature dependent, $\mathrm{pH}$ dependent and cation induced gelation. In situ gel forming drug delivery is a type of mucoadhesive drug delivery system. In contrast to very strong gels, they can be easily applied or used in liquid form to the site of drug absorption, where, they swell to form a strong gel that is capable of prolonging the residence time of the active substance. Both natural and synthetic polymers can be used for the production of in situ gels (Patel et al., 2012; Pallavi et al., 2016).

A peptic ulcer is a lesion in the mucosa of the stomach or duodenum in which acid and pepsin play a major role, the term is often used to encompass any gastric or duodenal ulceration. Peptic ulcers constitute a major problem in hyperacidity patients, which is due to inflammation of the stomach or duodenal mucosal lining of the GIT.

Roxatidine, a competitive histamine $\mathrm{H}_{2}-$ receptor antagonist, is used to treat gastrointestinal disorders such as gastric or duodenal ulcers, gastro esophageal reflux disease, and pathological hyper secretary conditions. Local availability of $\mathrm{H}_{2}$-antagonists in the stomach has a greater clinical significance in especially in the treatment of peptic ulcers (Tripathi et al., 2013, Ramana et al., 2016). 
In the present work, in situ gelling liquid formulation for sustained delivery of roxatidine is done because roxatidine is available in the market as tablets, capsules and in injection form. The formulation is prepared by using gellan gum and sodium alginate (different concentration), sodium citrate and calcium carbonate (source of cations) and roxatidine for the treatment of peptic ulcer disease.

\section{MATERIALS AND METHODS Materials and reagents}

Roxatidine acetate $\mathrm{HCl}$ was obtained from Win-Win chemical Co. Limited, China. Gellan gum was provided by $\mathrm{Hi}$ Media laboratories Ltd, Mumbai and sodium alginate was obtained from S.D. Fine-Chem limited, Mumbai. All the other materials used were of analytical grade.

\section{Preparation of in situ gelling systems}

Polymer solutions (gellan gum and sodium alginate) of various concentrations were prepared by adding to deionised water containing $0.17 \% \mathrm{w} / \mathrm{v}$ sodium citrate and heated to $90^{\circ} \mathrm{C}$ while stirring. After cooling to below $40^{\circ} \mathrm{C}$ appropriate amounts of calcium chloride $(0.05 \% \mathrm{w} / \mathrm{v})$, drug solution (roxatidine) and preservative (benzyl alcohol) were added to the polymer solution. Make up the volume up to $20 \mathrm{~mL}$ with water. The mixture was stirred by using a magnetic stirrer to ensure thorough mixing (Table I) (Harish et al., 2009; Divyesh et al., 2016).

\section{Evaluation of gels \\ FT-IR Absorption Spectrum}

FT-IR spectroscopy was carried out to check the compatibility between drug and polymer. The FT-IR spectra of the drug with polymers were compared with the standard FTIR spectrum of the pure drug (Roshan et al., 2015).

\section{Clarity test}

The clarity of formulated solutions was determined by visual inspection under black and white background. Black particles can be identified under white background and white particles can be identified under black background (Nirmal et al., 2010).

\section{pH measurement}

The $\mathrm{pH}$ was measured in each of the solutions of sodium alginate and gellangum based in situ solutions, using a calibrated digital $\mathrm{pH}$ meter at $27^{\circ} \mathrm{C}$. The measurements of $\mathrm{pH}$ of each data were in triplicate (Hareesh et al., 2012).

\section{Measurement of viscosity of sols}

Viscosity determinations for the prepared formulations were carried out on a Brook-field digital viscometer using spindle No 4. The viscosity of in situ gelling solutions was measured at different angular velocities at a temperature of $37^{\circ} \mathrm{C}$. A typical run comprised changing of the angular velocity from 0.0 to $100 \mathrm{pm}$. The averages of three readings were used to calculate the viscosity (Hareesh et al., 2012).

\section{Gelling capacity study}

The gelling capacity was determined by placing a drop of the system in a vial containing $2 \mathrm{~mL}$ of $0.1 \mathrm{~N} \mathrm{HCl}(\mathrm{pH} 1.2)$ freshly prepared and equilibrated at $37^{\circ} \mathrm{C}$ and visually assessing the gel formation and noting the time for gelation and the time taken for the gel formed to dissolve. Different grades were allotted as per the gel integrity, weight and rate of formation of a gel with respect to time (Patel et al., 2012).

\section{Spreadability}

To determine the Spreadability of the gel, approximately $1 \mathrm{~g}$ of the gel was placed at the center of the glass plate $(20 \times 20 \mathrm{~cm})$. This glass plate was covered with another glass plate of the same size. Next, the weight of $1000 \mathrm{~g}$ was carefully applied on the upper side of the plate; as a result, the gel was spread out in between the plates. After one minute, the weight was removed and the diameter of the spread area $(\mathrm{cm})$ was measured. This determination was carried out in triplicate (Patel et al., 2012).

\section{Determination of gel strength}

The method by which the properties of the polymeric system may be conveniently determined is texture profile analysis A TAXT2 Texture analyzer is used. The experiment was done by placing the gels in standard Beaker below an aluminum probe of $7.6 \mathrm{~cm}$ at room temperature. The instrument was set to the 
Table I Formulation of in situ gel of roxatidine with various polymers at different concentrations.

\begin{tabular}{lccccccccc}
\hline Formulation code & $\mathbf{G}_{1}$ & $\mathbf{G}_{2}$ & $\mathbf{G}_{3}$ & $\mathbf{G}_{4}$ & $\mathbf{S}_{1}$ & $\mathbf{S}_{2}$ & $\mathbf{S}_{3}$ & $\mathbf{S}_{4}$ & $\mathbf{S}_{5}$ \\
\hline Gellan gum $(\% \mathrm{w} / \mathrm{v})$ & 0.1 & 0.2 & 0.3 & 0.4 & - & - & - & - & - \\
Sodium alginate $(\% \mathrm{w} / \mathrm{v})$ & - & - & - & - & 0.2 & 0.4 & 0.6 & 0.8 & 1.0 \\
Sodium citrate $(\% \mathrm{w} / \mathrm{v})$ & 0.17 & 0.17 & 0.17 & 0.17 & 0.17 & 0.17 & 0.17 & 0.17 & 0.17 \\
Calcium chloride $(\% \mathrm{w} / \mathrm{v})$ & 0.05 & 0.05 & 0.05 & 0.05 & 0.05 & 0.05 & 0.05 & 0.05 & 0.05 \\
Preservative $(1.0 \% \mathrm{~m} / \mathrm{m})$ & 0.2 & 0.2 & 0.2 & 0.2 & 0.2 & 0.2 & 0.2 & 0.2 & 0.2 \\
Roxatidine $(\mathrm{mg})$ & 300 & 300 & 300 & 300 & 300 & 300 & 300 & 300 & 300 \\
Water & Qs & Qs & qs & qs & qs & Qs & qs & qs & qs \\
\hline
\end{tabular}

'gelling strength test' mode with a test-speed of $1.0 \mathrm{~mm} / \mathrm{s}$. An acquisition rate of 50 points per seconds and a trigger force of $5 \mathrm{~g}$ were selected. The force required to penetrate the gel was measured as gel strength in terms of grams (Hareesh et al., 2012).

\section{Determination of drug content}

Accurately $5 \mathrm{~mL}$ of the suspension was taken in a volumetric flask, dissolved in a small quantity of $0.1 \mathrm{~N} \mathrm{HCl}$. After the solutions were completely dissolved the volume were made up to $100 \mathrm{~mL}$ with $0.1 \mathrm{~N} \mathrm{HCl}$. From this solution $1 \mathrm{~mL}$ was taken and diluted to $10 \mathrm{~mL}$ respectively and then drug content was determined by measuring the absorbance at $275 \mathrm{~nm}$ by UV spectrophotometer (Patel $e t$ al., 2012).

\section{In situ release studies}

Drug release studies from the in-situ gel were carried out by using a cellophane membrane. Apparatus was designed as per the literature; a glass tube had a length of $10.5 \mathrm{~cm}$ and a diameter of $2.1 \mathrm{~cm}$. The lower base was tied with cellophane membrane and added a known quantity of in situ gel and this was placed in a beaker containing $100 \mathrm{~mL}$ of phosphate buffer $\mathrm{pH} 1.2$ as diffusion medium which is maintained at $37^{\circ} \mathrm{C}$ with $50 \mathrm{rpm}$. Samples $(5 \mathrm{~mL})$ were withdrawn at different time intervals from the reservoir till the gel was completely eroded (3h).The cumulative percent drug release was determined by spectrophoto-metric method (Hareesh et al., 2012).

\section{Ex vivo gelation study}

Ex vivo gelation study was performed to check in situ gel formation in mice. Animals (24h fasted mice) were divided in to two groups each contain 6 animals. Group -1: served as control and Group -2: served as treated.

In group-1 animal was sacrificed and stomach was removed, cut along with the greater curvature. In group-2 in situ gel formulation was administered orally and after the $3 \mathrm{~h}$ animal was sacrificed. Stomach was removed outside and cut along the greater curvature to observe weather gel forms or not (Patel et al., 2012).

\section{Stability study}

Prepared in situ gel formulation of roxatidine was stored in glass containers (well stoppered) to perform short-term stability studies for two months. Stability of the in situ gel formulation of roxatidine was monitored at room temperature $\left(25 \pm 1^{\circ} \mathrm{C}\right)$. Periodically samples were removed and evaluated for $\mathrm{pH}$, viscosity, drug content and in vitro release (Patel et al., 2012).

\section{RESULTS AND DISCUSSIONS FT-IR Spectrum}

All the characteristic peaks of roxatidine were present in the spectrum of drug and polymer mixture, indicating compatibility between drug and polymers. The spectrum confirmed that there is no significant change in chemical integrity of the drug.

\section{Clarity test}

Clarity test for the prepared formulations has done by visual inspection under black and white background. There was no evidence of contamination, the entire formulations pass clarity test (Table II). 
Table II. Characteristics of various in situ gel formulations

\begin{tabular}{cccccc}
\hline Formulation code & Clarity test & $\mathbf{p H}$ & $\begin{array}{c}\text { Spreadability } \\
\text { g.cm/s }\end{array}$ & Drug content (\%) & $\begin{array}{c}\text { Gelling } \\
\text { capacity }\end{array}$ \\
\hline G1 & Passes & 7.1 & $12 \pm 0.13$ & $94.96 \pm 0.002$ & + \\
G2 & Passes & 6.9 & $09 \pm 0.03$ & $95.65 \pm 0.013$ & ++ \\
G3 & Passes & 6.8 & $11 \pm 0.15$ & $98.08 \pm 0.045$ & +++ \\
G4 & Passes & 6.7 & $13 \pm 0.02$ & $92.26 \pm 0.056$ & +++ \\
S1 & Passes & 7.2 & $07 \pm 0.03$ & $96.66 \pm 0.086$ & + \\
S2 & Passes & 7.1 & $12 \pm 0.01$ & $95.14 \pm 0.074$ & + \\
S3 & Passes & 6.9 & $17 \pm 0.03$ & $94.10 \pm 0.045$ & ++ \\
S4 & Passes & 6.8 & $12 \pm 0.16$ & $92.29 \pm 0.046$ & +++ \\
S5 & Passes & 6.6 & $12 \pm 0.14$ & $91.49 \pm 0.089$ & +++ \\
\hline
\end{tabular}

+-Good, ++- average, +++ -excellent

Table III. Release exponent values and rate constant values for different formulations.

\begin{tabular}{cccccc}
\hline \multirow{2}{*}{ Formulation code } & \multicolumn{5}{c}{ Kinetic models } \\
\cline { 2 - 6 } & Zero order & First order & Higuchi & \multicolumn{2}{c}{ Korsmeyer et al. } \\
\cline { 2 - 6 } & $\mathrm{R}^{2}$ & $\mathrm{R}^{2}$ & $\mathrm{R}^{2}$ & $\mathrm{~N}$ & $\mathrm{R}^{2}$ \\
\hline G1 & 0.912 & 0.902 & 0.975 & 0.290 & 0.951 \\
G3 & 0.934 & 0.923 & 0.988 & 0.451 & 0.939 \\
G4 & 0.919 & 0.907 & 0.978 & 0.493 & 0.944 \\
S1 & 0.923 & 0.911 & 0.976 & 0.893 & 0.950 \\
S2 & 0.914 & 0.903 & 0.971 & 0.281 & 0.951 \\
S3 & 0.920 & 0.909 & 0.959 & 0.330 & 0.923 \\
S4 & 0.939 & 0.925 & 0.965 & 0.390 & 0.914 \\
S5 & 0.924 & 0.915 & 0.974 & 0.431 & 0.922 \\
& 0.959 & 0.945 & 0.993 & 0.499 & 0.945 \\
\hline
\end{tabular}

\section{Determination of pH}

The $\mathrm{pH}$ of in situ gels was determined using a calibrated $\mathrm{pH}$ meter. The readings were taken for average of 3 samples (Table II). Aqueous gellan gum and sodium alginate sols exhibited $\mathrm{pH}$ values in the range of 6.6 to 7.2 at $27^{\circ} \mathrm{C}$.

\section{Viscosity of the in situ sols}

The viscosity of in situ sols was determined by Brookfield viscometer (Table III). Among all formulations, S1 (sodium alginate $0.2 \%$ ) shows least viscosity (8.56 Pas) and G4 was more (15.98 Pas). The formulations S2 and G2 were nearly same (10.54 and $11.00 \mathrm{~Pa}$ s respectively). This says the increase in polymer concentration causes an increase in viscosity of the sols.

\section{In vitro gelling capacity}

It was found that the gel intensity was increased when the concentration of polymers was increased. Experimental part (Table II) have shown that the formulation G3, G4, S4, S5 were satisfactory to cause gelation.

\section{Gel strength}

The gel strength of in situ gels was determined by A TA-XT2 Texture analyzer (Table 2). Among all formulations, S1 (Sodium alginate $0.2 \%)$ shows least gel strength $(2.4 \mathrm{~g} / \mathrm{s})$ and G4 was more $(7.9 \mathrm{~g} / \mathrm{s})$. This says the increase in polymer concentration causes an increase in gel strength.

\section{Drug content}

Accurately $5 \mathrm{~mL}$ of the suspension was taken in a volumetric flask, dissolved in a small quantity of $0.1 \mathrm{~N} \mathrm{HCL}$. After the solutions were completely dissolved the volume were made up to $100 \mathrm{~mL}$ with $0.1 \mathrm{~N}$ HCL. From this solution $1 \mathrm{~mL}$ was taken and diluted to $10 \mathrm{~mL}$ respectively and then drug content was measured at $275 \mathrm{~nm}$ 
Mohammed Gulzar Ahmed

Table IV. Stability study

\begin{tabular}{ccccc}
\hline Time Period for sampling & $\mathbf{p H}$ & $\begin{array}{c}\text { Viscosity } \\
\mathbf{( P a} \cdot \mathbf{s})\end{array}$ & $\begin{array}{c}\text { Drug content } \\
\mathbf{( \% )}\end{array}$ & $\begin{array}{c}\text { \% Drug release } \\
\text { at 180 min. }\end{array}$ \\
\hline Initial & 6.7 & 15.98 & $92.26 \pm 0.056$ & $76.35 \pm 0.087$ \\
After 1Month & 6.7 & 15.99 & $92.24 \pm 0.058$ & $74.68 \pm 0.063$ \\
After2Month & 6.7 & 16.01 & $92.22 \pm 0.032$ & $73.43 \pm 0.048$ \\
\hline
\end{tabular}



Figure 1. Comparative drug release profile of the formulations (G1, G2, G3, G4, S1, S2, S3, S4 and S5)

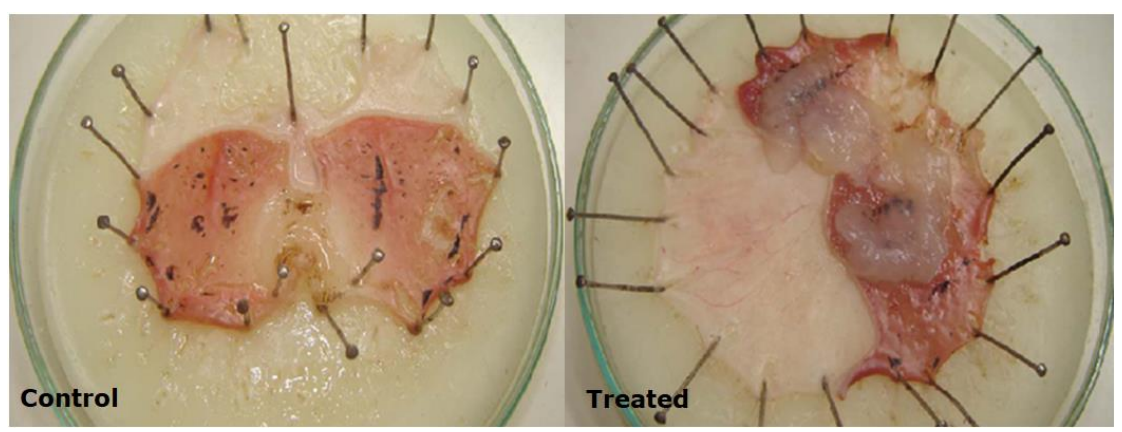

Figure 2. Ex vivo study in mice.

by UV spectrophotometer. Drug content of all formulations was found between 91.49 to 98.08 $\% \mathrm{~W} / \mathrm{W}$ (Table II). Further it was observed that the drug content values didn't obtain $100 \%$, this may be due to the embedment of the drug in the polymer, hence not came in solution.

\section{In situ release studies}

All the prepared formulation was subjected to in situ release studies by using phosphate buffer of $\mathrm{pH} 1.2$ in the diffusion medium for $180 \mathrm{~min}$. The formulations from G1-G4 containing a gellangum concentration of $(0.1-0.4 \% \mathrm{~W} / \mathrm{V})$ showed the drug released up to $91.56 \%$ and the formulation containing sodium alginate as a polymer of concentration $(0.2-1.0 \% \mathrm{~W} / \mathrm{V})$ has shown a maximum release of $97.38 \%$. Among the nine formulations the formulation S1 containing $(0.2 \% \mathrm{w} / \mathrm{v})$ of sodium alginate has shown the of drug released in a sustained manner up to the end $180 \mathrm{~min}$ when compared to other formulation.

\section{Release kinetics}

The examination of the correlation coefficient ' $r$ ' indicated that the drug release followed diffusion controlled mechanism from the in situ gels (Table III), as the values of ' $r$ ' for first order (ranged from 0.902 to 0.945 ) found to be less in comparison to zero order (ranged from 0.912 to 0.959 ) and Higuchi's square root of time (ranged from 0.959 to 0.993). It was understood to be predominant zero order release pattern. Further, to understand the drug release mechanism, the data were fitted into Peppas exponential model $\mathrm{M}^{\mathrm{t}} / \mathrm{M}^{\infty}=\mathrm{Kt}^{\mathrm{n}}$, where $\mathrm{M}^{\mathrm{t}} / \mathrm{M}^{\infty}$ is the fraction of drug released after time ' $\mathrm{t}$ ' and ' $\mathrm{K}$ ' is kinetic constant and ' $\mathrm{n}$ ' is 
release exponent which characterizes the drug transport mechanism. The values ' $n$ ' was in the range of 0.281 to 0.893 . The formulations $\mathrm{G} 1$, S1, S2, S3 and S4 were following fickian release mechanism ('n' values are less than 0.45), G2, G3 and S5 are indicating non-fickian release mechanism (' $n$ ' values are between $0.45-0,89$ ) and G4 is following super II release (' $n$ ' values are more than 0.89 ).

\section{Ex vivo gelation study}

Results of ex vivo gelation study showed that when the group 2 animals are sacrificed after $3 \mathrm{~h}$ the gel formed in the stomach was observed. It was observed that formed gel remained on a mucosal layer of the stomach to release the drug in a controlled manner (Figure 1 and 2).

\section{Stability study}

Short term stability study of in situ gel of roxatidine was carried out for 2 months at normal room temperature and humidity condition (Table IV).

\section{CONCLUSION}

In the present study in situ gel of roxatidine were prepared by using gellangum and sodium alginateof different concentration from $(0.1-0.4 \% \mathrm{~W} / \mathrm{V})$ and $(0.2-1.0 \% \mathrm{~W} / \mathrm{V})$ as the gel base. All the prepared formulation was evaluated in order to determine the suitability for the formulation. And all the prepared formulation provides intimate contact between the drug and the absorbing tissue which may result in high drug concentration in the local area. Based upon obtained results it can be concluded that prepared formulation is suitable for the treatment of pepticulcer. Out of this nine-different formulation the formulation containing $0.2 \% \mathrm{~W} / \mathrm{V}$ of sodium alginate is considered as an optimized formulation based on the evaluation parameter. The formulation S1 containing $(0.2 \% \mathrm{~W} / \mathrm{V})$ has shown gelation time within $4 \mathrm{~min}$ and $\mathrm{pH}$ of 1.2 which is suitable for the treatment of peptic ulcer. The in vitro release of $97.38 \%$ of drug release up to an end of $180 \mathrm{~min}$ which provides a controlled manner of drug release and prolong the residency time. Thus, it can be concluded that the prepared formulation gives a better patient compliance with increased bioavailability which is suitable for the treatment of peptic ulcer.

\section{ACKNOWLEDGEMENTS}

Authors were grateful to the Principal and Department of Pharmaceutics, Sri Adichunchanagiri College of Pharmacy, B.G Nagara for providing necessary facilities to carry out this research work.

\section{REFERENCES}

Divyesh HS., Hitesh DD., Pragna S., Alkesh KB., 2016. Formulation development and evaluation of a gastroretentive In situ oral gel of cefuroxime axetil. J Yun Pharm .8(4):324-329.

Hareesh BK., Gulzar MA., Narayana CR., 2012. Development and evaluation of in situ gels of Moxifloxacin for the treatment of Periodontitis. Indonesian $J$ Pharm. 23(3):141-146.

Harish NM., Prabhu P., Charyulu RN., Gulzar MA., Subrahmanyam EVS., 2009. Formulation and evaluation of in situ gels containing clotrimazole for oral candidiasis. Int J Pharm Sci.10(8):421-27.

http://home.intekom.com/pharm/hmr/roxit. $\underline{\mathrm{html}}$

Pallavi C., Pratibha., Gnanrajan G., Preethi K., 2016. In situ gel: A review. Ind J Pharm Biol Res. 4(2): 11-19

Patel NA., Mahesh KS., Ravi K., Senthil A., Viral GP., 2012. Development and evaluation of oral gastro-retentive in situ gel of famotidine. Indo-Global Res J Pharm Sci. 2(1):238-43.

Ramana BV., Jalalu SS., Swapna C., et al., 2016. Design and development of floating in situ gel of pantoprazole. Scholar Res Lib. 8(8): 239-249.

Roshan RM., Vaishali G., Gupta S., 2015. Novel study in sustained release drug delivery system: A Review. Int J Pharm Med Res. 3(2): 204-215.

Tripathi KD., 2013. Drugs for peptic ulcer in essentials of medical pharmacology.7th edn. New Delhi: Jaypee Brothers Medical Publishers. 585-91. 